\title{
Fault detection and diagnosis of photovoltaic system using fuzzy logic control
}

\author{
Sayed A. Zaki ${ }^{1,3,}$, Honglu $\mathrm{Zhu}^{1,2}$, Jianxi Yao ${ }^{1,2}$ \\ ${ }^{1}$ School of Renewable and Clean Energy, North China Electric Power University, 102206, Beijing, China \\ ${ }^{2}$ The State Key Laboratory of Alternate Electrical Power System with Renewable Energy Sources, North China Electric Power \\ University, 102206, Beijing, China. \\ ${ }^{3}$ Faculty of Engineering, Cairo University, Giza, Egypt
}

\begin{abstract}
Among several renewable energy resources, Solar has great potential to solve the world's energy problems. With the rapid expansion and installation of PV system worldwide, fault detection and diagnosis has become the most significant issue in order to raise the system efficiency and reduce the maintenance cost as well as repair time. This paper presented a method for monitoring, identifying, and detecting different faults in PV array. This method is built based on comparing the measured electrical parameters with its theoretical parameters in case of normal and faulty conditions of PV array. For this purpose, three ratios of open circuit voltage, current, and voltage are obtained with their associated limits in order to detect eight different faults. Moreover, the fuzzy logic control FLC method is performed for studying the failure configuration and categorizing correctly the different faults occurred. The outcomes obtained by performing the different faults representing permanent and temporary faults demonstrated that the FLC was equipped to precisely identify the faults upon their occurring. Different simulated and experimental tests are conducted to demonstrate the performance of the proposed method.
\end{abstract}

\section{Introduction}

Over the last few decades, the use of PV systems has spread rapidly all over the world in different applications, from space to the residential, commercial, and industrial applications [1]. High use of PV panels has brought high $\mathrm{PV}$ component failure rate as well. This high rate is because of many reasons such as; short circuit between modules; an open circuit in different strings, etc. These failures greatly influence on the operating efficiency of the PV generation systems and the performance of the PV system work. Therefore, many types of research and developments in ref. [2] made good progress using online fault diagnosis to increase system reliability and performance by early fault detection.

Different faults can be categorized into temporary and permanent faults in PV arrays, and both are responsible for reducing the output power and solar energy generated compared with healthy operating conditions [3]. Although the temporary faults occurred for a short period in reality, the protection devices need to discriminate this condition from permanent fault conditions for preventing wrong shutdowns [4]. Therefore, to reduce the unavailability time, increase the stability and efficiency of PV systems, different fault diagnosis and detection techniques are needed to ensure the continuity of solar generation [5].

There are many fault detection methods used in the GCPV systems. In [6], automatic supervision by OPC technology-based monitoring by calculating Voltage and Current Ratios VR, and IR is used to detect the different faults. Some other techniques such as in ref. [7-8] are implemented based on the real-time environmental conditions and some PV parameters, however, the drawback of this methods is the high cost of equipment. Moreover, Partial Shading PS in the GCPV plant using statistical methods is discussed and validated using Ratios VR\& PR [9-10].

Recently, a number of fault diagnosis methods based on artificial intelligence techniques are adopted to increase the detection rate and right classification such as Fuzzy Logic Control FLC [7, 10], Neural Network [2,11], both Neural and FLC [10,12], Genetic Algorithm [13], or MATLAB $[4,6]$. Currently, the FLC is widely used with GCPV systems, Such as $[10,12]$ which presented FLC to detect the faulty modules, but couldn't discriminate between open circuit and short circuit faults.

The work presented in this paper is to introduce a new technique to detect and diagnose the different types of faults occurring in the PV power plants using Sugeno FLC method. This method is used as an artificial method to increase the accuracy of fault identification and fast diagnosis. The proposed detection method depends on the analysis set of three input ratios which are Open Circuit Ratio OCR, Current Ratio IR, and Voltage Ratio VR. Calculating these ratios is performed using the measured and simulated under normal and faulty conditions. The fault detection method is implemented using FLC-based

* Corresponding author: eng_sayed_002010@yahoo.com 
method and MATLAB Simulink tool to identify the type of the fault. The selected faults in this work are PS, PS with bypass diode failure, open circuit, short circuit, snow falling, and bird or tree leaves dropping on PV plant. The algorithm is validated using $3.34 \mathrm{kWp}$ solar PV system installed at the roof of North China Electric Power University (NCEPU).

The paper is organized as follows: the next section presents the different faults types in a PV plant including the solar PV modeling. Then, the methodology of the work is discussed in Section 3. Section 4 discusses Sugeno FLC implementation. In section 5, the experimental test results, discussion, and comparison with other methods are provided. Section 6 provides conclusion remarks.

\section{Different faults in PV array}

In this section, the modeling of PV array is presented by defining the mathematical equations, then the different faults may occurring in PV system and their characteristics are investigated in detail to extract the different features of every fault case.

\subsection{Solar PV model}

The most commonly utilized models of PV module essentially incorporate the one diode (or called the fiveparameters model), the two-diode, the four-parameter model, etc. They can be utilized generally for various application events or distinctive purposes. In this paper, the one-diode model is utilized as a mathematical model for obtaining the relation between the module current and voltage. Then, the DC side of the PV system is modeled using Matlab Simulink. The voltage and current Values of the PV panel can be calculated as shown in Fig. 1, which can be expressed as [11]:

$$
\begin{gathered}
I=I_{L}-I_{D}-I_{S h} \\
I=I_{L}-I_{O}\left(e^{\frac{V+I R_{S}}{N_{S} V_{T}}}-1\right)-\left(\frac{V+I R_{S}}{R_{S h}}\right)
\end{gathered}
$$

Where $I_{L}$ is the light-generated current at Standard Test Condition STC, $I_{D}$ is the diode current, $I_{S h}$ is the current in shunt resistance, $I_{O}$ is the dark saturation current at STC, $R_{s}$ is the panel series resistance, $R_{s h}$ is the panel shunt resistance, $N_{S}$ is the number of series cells in the PV panel and $V_{T}$ is the thermal voltage and it can be defined based on:

$$
V_{T}=\frac{A K T}{q}
$$

Where $A$ the ideal diode factor, $K$ is Boltzmann's constant and $q$ is the charge of the electron.

Although, the environmental conditions of solar radiation and temperature have a direct influence on the PV modules output characteristics. Therefore, their effect should be taken into consideration during studying the different features in case of normal and fault cases.

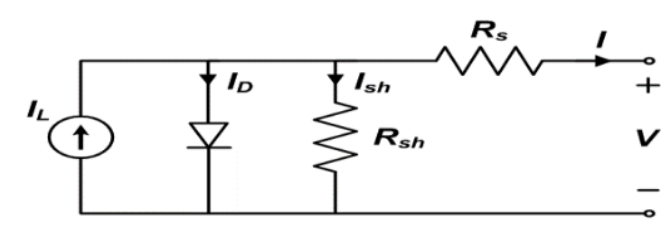

Fig. 1. The single diode model of the PV module.

\subsection{Faults of PV array and the output features}

Faults in the PV system not only decrease output power generation, but it also reduces the availability and reliability of the whole system. Therefore, in order to maximize the output power, identifying the faults in the PV system is extremely important. There are many faults affecting on the DC side the PV system temporarily or may be permanent.

This work aims to identify, detect, and localize the faults occurring in the PV array. The selected faults in this work are discussed in Table 1. In addition, the MATLAB Simulink model is built to extract the different features of these faults from $I-V$, and $P-V$ curves as shown in the following section.

Table 1. The different selected faults occurred in the PV system

\begin{tabular}{|c|c|}
\hline Fault type & Symbol \\
\hline Normal operation & F0 \\
\hline PS effect without BP failure & F1 \\
\hline PS effect with BP failure & F2 \\
\hline Two modules short circuit in PV array & F3 \\
\hline Four modules short circuit in PV array & F4 \\
\hline $\begin{array}{c}\text { Two modules open circuit without BP } \\
\text { failure in modules }\end{array}$ & F5 \\
\hline $\begin{array}{c}\text { Four modules open circuit without BP } \\
\text { failure in modules }\end{array}$ & F6 \\
\hline Snow falling & F7 \\
\hline Bird or tree leaves dropping & F8 \\
\hline
\end{tabular}

\subsubsection{Partial Shading PS fault without bypass diode failure (F1)}

The shading profiles can be extremely unexpected due to non-uniform of radiation during occurring that condition. The all PV array is assumed shaded with solar radiation $\mathrm{G}=500 \mathrm{~W} / \mathrm{m}^{2}$ at $25^{\circ} \mathrm{C}$ of temperature $\mathrm{T}$ at Standard Test Condition STC $\left(\mathrm{G}=1000 \mathrm{~W} / \mathrm{m}^{2}\right.$, and $\left.\mathrm{T}=25^{\circ} \mathrm{C}\right)$. The $I-V$ and $P-V$ characteristics are illustrated in Fig. 2, for normal and fault cases analysis. In case of PS situation, the short circuit current $I_{s c}$ remains constant, but the open-circuit voltage $V_{o c}$ significantly reduces with the increase of the shaded modules.

\subsubsection{Partial shading fault with bypass diode failure (F2)}

The assumption of this case is all bypass diodes that connected parallel with the PV modules are open circuited during the case of PS occurring. The received solar radiation density is assumed to be $\mathrm{G}=500 \mathrm{~W} / \mathrm{m}^{2}$ at $25{ }^{\circ} \mathrm{C}$. $I-V$ and $P-V$ characteristics of this case cases are shown in Fig. 2. In this case, the maximum power $P_{\text {max }}$, 
and $V_{o c}$ of the PV system significantly decrease due to the voltage drop lost on the shaded modules while bypass diode not working properly, while $I_{S C}$ rests the same of previous PS.

\subsubsection{The short circuit fault at STC (F3, and F4)}

The short-circuit fault is an accidental interconnection in the current carrying conductor, PV cells/modules cracking, or connections between modules with considerable effect on the series and parallel resistance of the PV array. In this part, it's assumed in F3 and F4 that PV modules have a short circuit problem in two modules, and four modules respectively. From shown in Fig. 2, $I_{s c}$ nearly the same, while $V_{o c}$ and $P_{\max }$ of these cases significantly reduce with the rise in the numbers of shorted modules.

\subsubsection{Open circuit fault at STC (F5, and F6)}

The open-circuit fault is an unexpected disconnection inside the PV module conductor which influence on the array total resistance during the fault. In this part, we assume in F5 and F6 that PV modules have a disconnection problem in two modules and four modules, respectively while the bypass diode is connected in parallel with the modules. $I-V$ and $P-V$ curves have been compared with the PV array in case of short circuit case, as shown in Fig. 2. $I_{s c}$ almost remains constant, while $V_{o c}$ and $P_{\max }$ of these cases slightly drop with the increase of the disconnected module numbers due to voltage drop on the bypass diode equals $0.8 \mathrm{v}$ across each faulty module, which directly has a significant influence on the total output power, and voltage. This means power gets lost in bypass diode which is given by [13]:

$$
P_{\text {loss }}=I_{\text {mod }} * V_{B p}
$$

Where, $I_{\bmod }$ is the module output current and $V_{B p}$ is the voltage drop across the bypass diode.

\subsubsection{Snow cover fault (F7)}

This fault occurs due to snow falling only in winter as a temporary fault causes large energy losses for system operation. Assume in this fault, the all PV array only receives $10 \%$ solar radiation compared to uncovered PV modules under the same temperature at STC. As shown in Fig. 2, $I_{s c}$ and $P_{\max }$ dramatically decrease due to reduction in the solar radiation, while $V_{o c}$ reduces significantly with the rise in the number of covered modules by snow.

\subsubsection{Bird or tree leaves dropping at STC (F8)}

This kind of temporary fault occurs due to presence of bird or leaves prevent totally the solar radiation to be received by the PV module. It's assumed that one full module is fully covered, i.e. the solar radiation equals 0 $\mathrm{W} / \mathrm{m}^{2}$ at a normal temperature, and the remaining PV modules receives the normal solar radiation. As shown in Fig. 2, $I_{s c}$ is the same, while $V_{o c}$ and $P_{\max }$ significantly reduce with the rise in the numbers of covered modules.

For detecting these kinds of faults, a method of comparing the ratios with their threshold high and low limits is discussed and implemented using FLC algorithm.

\section{Methodology of PV faults diagnosis and detection algorithm}

The fault diagnosis technique used in this paper is based on the threshold limits, furthermore, one normal and eight faulty categories are discussed and detected, then, the ratios between the measured and the simulated parameters of PV string are compared with threshold limits in order to detect the exact type of fault. Moreover, the analysis of the main attributes in the $I-V$ characteristics of each string in the PV array plays the main role to localize faults accurately.

Three ratios have been identified to detect different types of faults in DC side; $O C R, V R$, and $I R$ have been used to categorize the region where the fault has occurred. All ratios can be calculated using the following expressions:

$$
\begin{aligned}
O C R & =V_{o c, t h} / V_{o c, \text { meas }} \\
V R & =V_{m, t h} / V_{m, \text { meas }} \\
I R & =I_{m, t h} / I_{m, \text { meas }}
\end{aligned}
$$

where $V_{o c, t h}, V_{m, t h}, I_{m, t h}$ are the theoretical parameters of $V_{o c}, V_{m}$, and $I_{m}$ generated by the PV system MATLAB model respectively, while $V_{o c \text {,meas }}, V_{\text {m,meas }}$, and $I_{m \text { meas }}$ represent the measured data of same parameters.
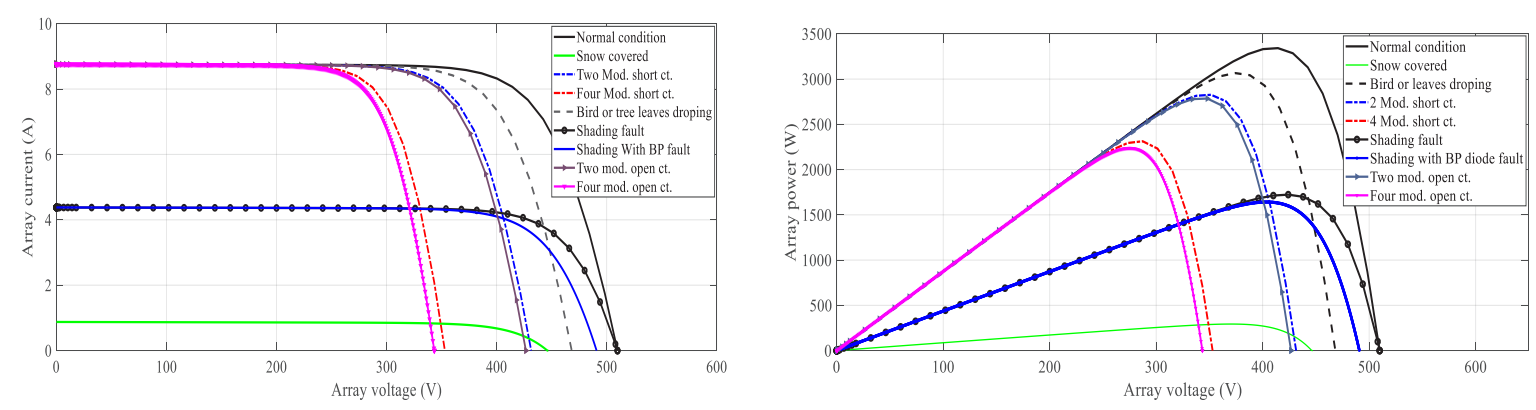

Fig. 2. The I-V, and P-V curves of normal and faulty condition of the PV system at STC. 
In fact, the efficiency of the MPPT device used in the PV system has not the efficiency of $100 \%$, in this paper, we assume the MPPT efficiency greater than or equal $95 \%$ ). Therefore, these ratios are subjected to high and low limits.

\subsection{High limit}

Where the maximum operating efficiency of the MPPT device is applied, therefore, the high limit for OCR, VR and IR ratios shown in Table 2 is expressed by:

$$
\begin{aligned}
H L_{-} O C R & =V_{o c, n}(G, T) / V_{o c, f}(G, T) \\
H L_{-} V R & =V_{m, n}(G, T) / V_{m, f}(G, T) \\
H L_{-} I R & =I_{m, n}(G, T) / I_{m, f}(G, T)
\end{aligned}
$$

Where $V_{o c, n}(G, T), V_{m, n}(G, T)$, and $I_{m, n}(G, T)$ are the theoretical parameters of $V_{o c}, V_{m}$, and $I_{m}$ at normal conditions respectively at $\mathrm{G}$ and $\mathrm{T}$, while $V_{o c, f}(G, T), V_{m, f}(G, T)$, and $I_{m, f}(G, T)$ are the theoretical data of the same parameters in case of fault conditions at any $\mathrm{G}, \mathrm{T}$ respectively.

\subsection{Low limit}

Where the minimum efficiency of the MPPT device $\eta_{\text {мPPт }}$ is applied. The low limits shown in Table 2 can be expressed for every case by the following formulas:

$$
\begin{aligned}
L L_{-} O C R & =V_{o c, n}(G, T) /\left(V_{o c, f}(G, T) * \eta_{M P P T}\right) \\
L L_{-} V R & =V_{m, n}(G, T) /\left(V_{m, f}(G, T) * \eta_{M P P T}\right) \\
L L_{-} I R & =I_{m, n}(G, T) /\left(I_{m, f}(G, T) * \eta_{M P P T}\right)
\end{aligned}
$$

The difference between this method and the other similar fault detection techniques defined in literature is that this method discusses a number of temporary faults such as snow cover and bird or tree leaves dropping, also, it differentiates between the faults with similar features. In addition, the proposed fault method can apply for an unexpected variation of $\mathrm{G}$ and $\mathrm{T}$.

\section{Fuzzy logic control implementation}

FLC is one of the modern artificial techniques used in fault diagnosis in the PV system. A concise diagram of the ongoing productions on FL schemes configuration is displayed in [12]. The FLC system attributes are built based on the condition of if, and then statement between numbers of uncertain input set of data in order to give decisions called the membership function output.

In this paper, Sugeno FL classifier is exhibited and confirmed experimentally for its characteristics which have been discussed in [12]. The architecture of the implementation is based on the Max-Min arrangement procedure with a centroid type for the defuzzification as shown in Fig. 3, moreover, eight FL rules were selected and implemented in order to detect accurately the occurred faults in the PV array as presented in Table 1.

From the previous analysis of the $O C R, V R$, and $I R$ in the PV system, the fault diagnosis scenarios can be obtained. Each $O C R, V R$, and $I R$ region represent a fault case could happen in the PV system. While $V_{o c}, V_{m}$ and $I_{m}$ have a rapid change during each case of normal and abnormal scenario, they play the main role in the fault detection and diagnosis scenarios.

The output FLC algorithm is based on the comparison of the three ratios with the calculated threshold high and low limit values, then send an alarm to the operator for taking correct action as shown in Fig. 4 which illustrates the flowchart of the proposed method.

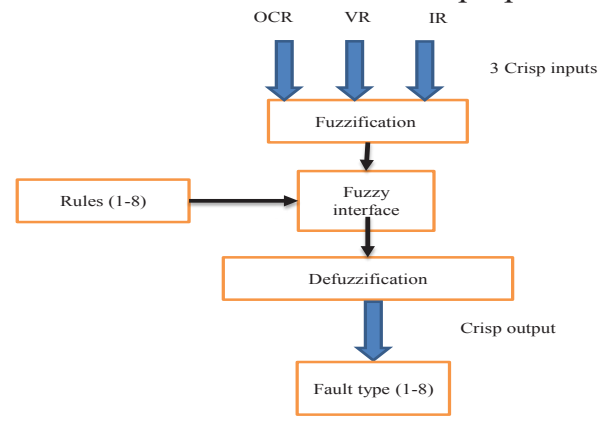

Fig. 3. The Sugeno FLC implementation.

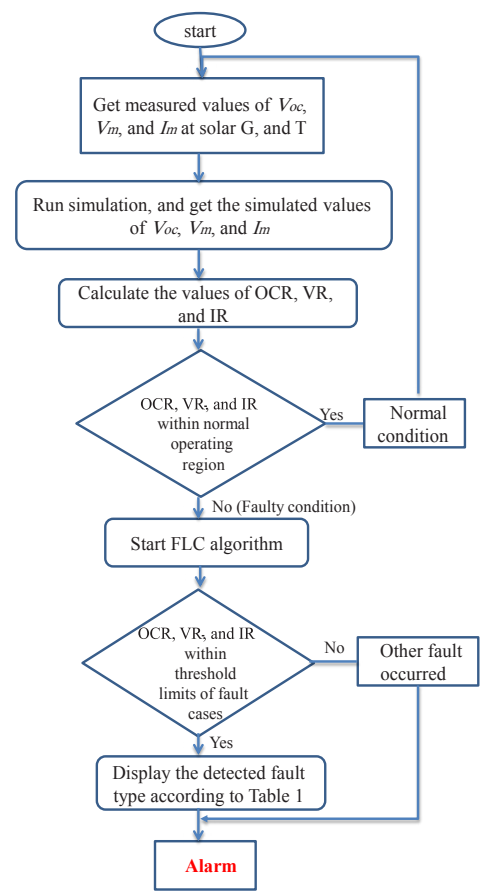

Fig. 4. The flowchart of the proposed fault detection method.

Table 2. The overall fuzzy logic system classifier system design in normal and faulty conditions

\begin{tabular}{|c|c|c|c|c|c|c|c|c|}
\hline \multirow{2}{*}{ Case } & \multirow{2}{*}{ PS\% } & \multicolumn{2}{|c|}{$\begin{array}{c}\text { OCR } \\
\text { Limits }\end{array}$} & \multicolumn{2}{c|}{ VR limits } & \multicolumn{2}{|c|}{ IR limits } & $\begin{array}{c}\text { F. } \\
\text { Classifier } \\
\text { region }\end{array}$ \\
\cline { 3 - 8 } & & Min & Max & Min & Max & Min & Max & 0 \\
\hline F0 & 0 & 1 & 1.05 & 1 & 1.05 & 1 & 1.05 & 0 \\
\hline F1 & 50 & 1 & 1.03 & 0.97 & 1.03 & 1.97 & 2.11 & 1 \\
\hline F2 & 50 & 1.04 & 1.09 & 1.03 & 1.07 & 2.03 & 2.14 & 2 \\
\hline F3 & 0 & 1.17 & 1.2 & 1.16 & 1.23 & 1 & 1.01 & 3 \\
\hline F4 & 0 & 1.44 & 1.48 & 1.42 & 1.49 & 1 & 1.01 & 4 \\
\hline F5 & 0 & 1.18 & 1.25 & 1.17 & 1.24 & 1.01 & 1.03 & 5 \\
\hline F6 & 0 & 1.48 & 1.56 & 1.49 & 1.56 & 1.01 & 1.04 & 6 \\
\hline F7 & 0 & 1 & 1.15 & 1.11 & 1.25 & 1.08 & 10 & 7 \\
\hline F8 & 0 & 1.08 & 1.14 & 1.05 & 1.25 & 0.97 & 1.05 & 8 \\
\hline
\end{tabular}




\section{Results and discussion}

\subsection{PV system and data collection}

The PV array consists of 13 monocrystalline silicon JKM245 P-60-I PV modules, each module has 60 cells with 3 bypass diodes (one diode per 20 cells) connected in parallel with the cells in reverse connection.. Each module generates 245 Watt output power under STC, AM1.5 as shown in Table 3. The PV array has 13 modules connected in series and one parallel string and installed on the roof of NCEPU, Beijing, China as shown in Fig. 5 which shows the experimental setup of the PV system. The measurement of power, voltage, and currents are obtained and collected by internal sensors every one minute over all day $13^{\text {th }}$ of April 2017. Table 4 shows a full day tested cases at normal radiation and temperature which are tested to the PV array. Furthermore, a comparison between the theoretical output vs. the real-time faulted data of PV system during the examined cases of faults are conducted to calculate the values of $O C R, V R$, and $I R$ as shown in Fig. 6.

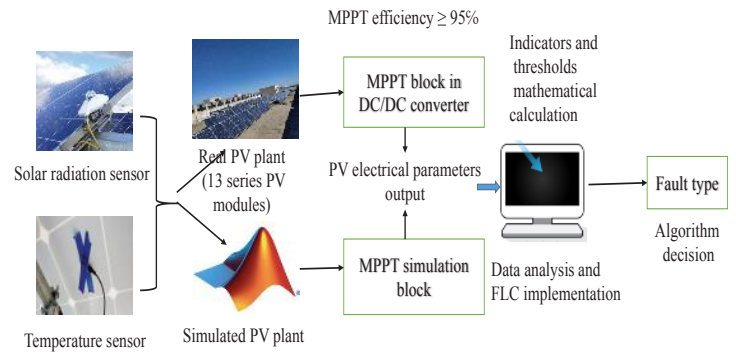

Fig. 5. Experimental setup of the fault detection method on the PV system.

Table 3. Basic parameters for the module at STC condition.

\begin{tabular}{|c|c|c|}
\hline Parameter & Variable & Value \\
\hline Maximum power (W) & $P_{\max , S T C}$ & 245 \\
\hline Voltage at max. power (V) & $V_{m, S T C}$ & 30.1 \\
\hline Current at max. power (A) & $I_{m, S T C}$ & 8.14 \\
\hline Open circuit voltage (V) & $V_{O C, S T C}$ & 37.5 \\
\hline Short circuit current (A) & $I_{S C, S T C}$ & 8.76 \\
\hline
\end{tabular}

Table 4. A full day implemented different cases of normal and faulty conditions.

\begin{tabular}{|c|c|c|c|c|}
\hline case & $\begin{array}{c}\text { Start } \\
\text { time }\end{array}$ & $\begin{array}{c}\text { End } \\
\text { time }\end{array}$ & $\begin{array}{c}\text { Condition of PV } \\
\text { system }\end{array}$ & $\begin{array}{c}\text { No. of } \\
\text { samples } \\
\text { to FLC }\end{array}$ \\
\hline 1 & $6: 00$ & $7: 59$ & $\begin{array}{c}\text { Two mod. Short } \\
\text { circuit F3 }\end{array}$ & 120 \\
\hline 2 & $8: 00$ & $9: 59$ & $\begin{array}{c}\text { Four mod. Open } \\
\text { circuit F6 }\end{array}$ & 120 \\
\hline 3 & $10: 00$ & $11: 59$ & $\begin{array}{c}\text { PS w/o Bp. diode } \\
\text { failure F1 }\end{array}$ & 120 \\
\hline 4 & $12: 00$ & $13: 59$ & $\begin{array}{c}\text { Normal condition } \\
\text { F0 }\end{array}$ & 120 \\
\hline 5 & $14: 00$ & $15: 59$ & $\begin{array}{c}\text { Snow falling fault } \\
\text { F7 }\end{array}$ & 120 \\
\hline 6 & $16: 00$ & $17: 59$ & $\begin{array}{c}\text { Bird or tree leaves } \\
\text { dropping fault F8 }\end{array}$ & 120 \\
\cline { 4 - 5 } & & & \multicolumn{2}{c}{ Total=720 } \\
\cline { 4 - 5 }
\end{tabular}

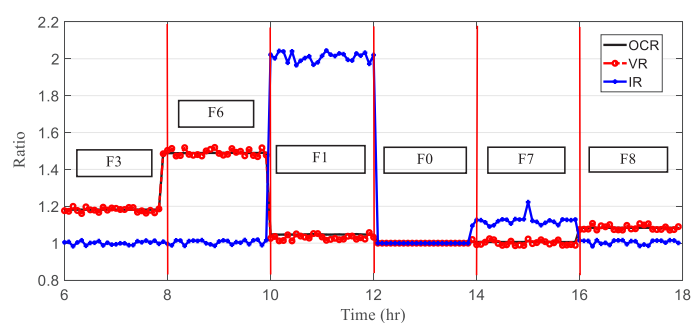

Fig. 6. The calculated values of $O C R, V R$, and $I R$ in different fault and normal cases.

\subsection{Analysis of the testing FLC results}

The membership output of the different fault cases for Sugeno FL method is shown in Fig. 7. Each examined PV condition is categorized in the shown figure. For example, case 1 represents F1 fault, for this selected PV fault case, the output of the Sugeno fuzzy algorithm is equal to 3. Similarly, case 5 and 6 represents the F7, and F8 respectively. In this situation, the output of the fuzzy algorithm is equal to 7 and 8 respectively.

Most of the samples data during the testing time period are founded within the low and high threshold limits. Although, in each case, some samples couldn't be detected correctly which called out-of-region samples. This state is happening due to the high number of faulty regions identified by the fuzzy system and the calculation of three ratios may be affected by the sensors efficiency. The detection accuracy (DA) for each examined case can be calculated by:

$D A=\frac{\text { total samples }- \text { out of region samples }}{\text { total samples }}$

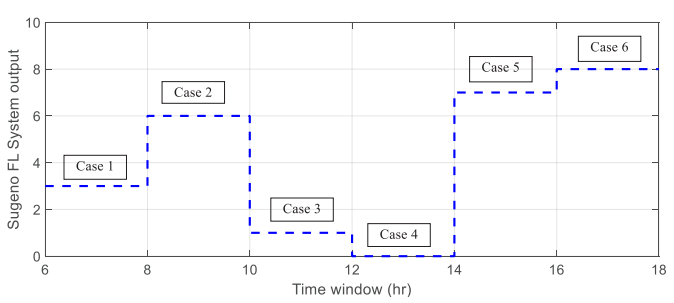

Fig. 7. The Sugeno fuzzy logic output for the different examined six cases.

Table 5. The output DA without and with the FLC system.

\begin{tabular}{|c|c|c|c|c|c|}
\hline \multirow[b]{2}{*}{ Case } & \multirow[b]{2}{*}{ Scenario } & \multicolumn{2}{|c|}{ Without FLC } & \multicolumn{2}{|c|}{ With FLC } \\
\hline & & $\begin{array}{c}\text { Out of region } \\
\text { samples }\end{array}$ & DA (\%) & $\begin{array}{c}\text { Out of } \\
\text { region } \\
\text { samples }\end{array}$ & $\begin{array}{l}\text { DA } \\
(\%)\end{array}$ \\
\hline 1 & F3 & 8 & 93.3 & 1 & 99.1 \\
\hline 2 & F6 & 6 & 95 & 2 & 98.3 \\
\hline 3 & F1 & 5 & 95.8 & 1 & 99.1 \\
\hline 4 & F0 & 4 & 96.6 & 0 & 100 \\
\hline 5 & F7 & 5 & 95.8 & 1 & 99.1 \\
\hline 6 & F8 & 7 & 94.2 & 2 & 98.3 \\
\hline
\end{tabular}

For each case discussed in Table 4, the FL method can decrease the out of region samples when compared with before considering the FLC system as shown in Table 5. It clearly ensures that most of the samples are classified accurately using the fuzzy classifier. Moreover, the total DA after using FLC system with only out of 
region samples 7 from total samples 720 equals $99 \%$ which improves the monitoring of the PV system. As can we see that, the proposed method can precisely and effectively classify, and detect the different faults data.

\subsection{Comparison with other methods}

This step is implemented to check the efficiency of the proposed FLC technique, this evaluation is obtained by comparing with the method in Ref. [11] that ANN to identify and detect eight different faults. The comparison between the parameters and the decision output of each method is obtained in Table 6. We can notice that, the ANN model in Ref. [11] can't identify the all presented fault types (as shown in case 3, Table 6), moreover, it has low classification rate which has been implemented in the confusion matrix the paper compared with the proposed method.

The comparison with other method notified that the proposed FLC method has a high DA and classification rate. However, increasing the number of rules using in FLC method may lead to more computational time. Also, the proposed method accuracy may be affected by the efficiency of the sensors used in measurements.

Table 6. Comparison between the proposed FLC method Results and the ANN method in Ref. [11].

\begin{tabular}{|c|c|c|c|c|c|}
\hline \multirow{2}{*}{ Case } & \multirow{2}{*}{$\begin{array}{c}\text { Scena } \\
\text { rio }\end{array}$} & \multicolumn{2}{|c|}{ ANN method } & \multicolumn{2}{|c|}{$\begin{array}{c}\text { Proposed FLC } \\
\text { method }\end{array}$} \\
\hline & & Parameters & Decision & Parameters & $\begin{array}{c}\text { Decis } \\
\text { on }\end{array}$ \\
\hline 1 & $\begin{array}{l}\text { Two } \\
\text { mod. } \\
\text { short } \\
\text { circuit }\end{array}$ & $\begin{array}{c}\text { Algorithm 1: } \\
\mathrm{N}=1, \mathrm{C} 1=0.01, \mathrm{C} 2= \\
0.01, \mathrm{~T} 1=0.35 \mathrm{~A} \\
\text { Algorithm } 2: \\
R V_{o c}=0.82, R V_{m p p}= \\
0.83 \\
R I_{m p p}=0.99\end{array}$ & $\begin{array}{c}\text { Group of } \\
\text { faults not } \\
\text { discriminab } \\
\text { le }\end{array}$ & $\begin{array}{c}\mathrm{OCR}=1.18 \\
\mathrm{VR}=1.17 \\
\mathrm{IR}=1\end{array}$ & F3 \\
\hline 2 & \begin{tabular}{|c|} 
Four \\
mod. \\
open \\
circuit
\end{tabular} & $\begin{array}{c}\text { Algorithm 1: } \\
\mathrm{N}=1, \mathrm{C} 1=0.01, \\
\mathrm{C} 2=0.02, \mathrm{~T} 1=0.35 \mathrm{~A}\end{array}$ & \begin{tabular}{|c|} 
Open \\
circuit fault \\
in any cell \\
or (module) \\
\end{tabular} & $\begin{array}{c}\mathrm{OCR}=1.48 \\
\mathrm{VR}=1.49 \\
\mathrm{IR}=1.01\end{array}$ & F6 \\
\hline 3 & $\begin{array}{l}\text { Snow } \\
\text { cover }\end{array}$ & $\begin{array}{c}\text { Algorithm 1: } \\
\mathrm{N}=1, \mathrm{C} 1=0.52, \\
\mathrm{C} 2=0.5, \mathrm{~T} 1=0.35 \mathrm{~A}\end{array}$ & $\begin{array}{l}\text { Shadow } \\
\text { with faulty } \\
\text { bypass } \\
\text { diode }\end{array}$ & $\begin{array}{c}\mathrm{OCR}=1.1 \\
\mathrm{VR}=1.15 \\
\mathrm{IR}=2\end{array}$ & F7 \\
\hline
\end{tabular}

$\mathrm{C} 1$ : reduction in the $I_{S C} ; \mathrm{C} 2$ : reduction or an increase in the $I_{M} ; \mathrm{N}$ : number of MPPs; T1: Threshold $I_{s c}$ at STC,

\section{Conclusion}

In this paper, a new technique for monitoring and detecting the faults in the PV system is discussed. This technique is carried out based on three ratios of the $O C R$, $V R$, and $I R$ with their thresholds high and low limits.

In order to detect failures in the PV system, firstly, eight faults were presented in detail to evaluate the performance of the algorithm on the PV system. All the experimental faults were accurately identified, classified by the proposed method. Moreover, the total DA after using FLC system equals 99\% which improves the monitoring of the PV system.
In addition, the FLC is adopted in this study due to its straightforwardness and high computational speed, and it can be applicable in case of large scale PV plant due to low monitoring cost and economic benefits.

\section{References}

1. E. Kaplani, Detection of degradation effects in fieldaged c-Si solar cells through IR thermography and digital image processing, Int. J. of Photovoltaic Energy, 11, (2012).

2. A.T. Lahiania, A. B. Abdelghani, I. S. Belkhodja, Fault detection and monitoring systems for photovoltaic installations: A review, Renew. and Sustain. Energy Review, 82, 12 (2018)

3. A. Chokor, M. El Asmar, S. V. Lokanath, A Review of PV DC Systems Prognostics and Health Manag.: Challenges and Opportunities, PHM Conf., 6 oct., Denver, Colorado, 12(2016).

4. R. Hariharan, M. Chakkarapani, G. S. Ilango, $A$ Method to Detect Photovoltaic Array Faults and PS in PV Systems, IEEE J. of Photovoltaic, 6(5), 7(2016).

5. R. Khenfer, et. al, Faults Detection in a PV Generator by Using Matlab Simulink and the chipKIT Max32 Board, Int. J. of Photovoltaic Energy, 9(2014).

6. S. Silvestre, et. al., Remote supervision and fault detection on OPC monitored PV systems, Sol. Energy, 137, 9(2016).

7. W. Chine, A. Mellit, A. M. Pavan, S. A. Kalogirou., Fault detection method for grid-connected photovoltaic plants". Ren. Energy, 66, 11(2014).

8. R. Platon, J. Martel, N. Woodruff, T. Y. Chau, Online fault detection in PV systems". IEEE Trans. Sustain. Energy, 6(4), 7(2015).

9. M. Dhimish, V. Holmes, B. Mehrdadi, M. Dales, Fault detection algorithm for GCPV plants, Sol. Energy., 137, 9(2016).

10. M. Dhimish, V. Holmes, B. Mehrdadi, M. Dales, Diagnostic method for photovoltaic systems based on six layer detection algorithm, Elec. Power Sys. Res. 151, 13(2017).

11. W. Chine, A. Mellit, V. Lughi, A. Malek, G. Sulligoi, A. M. Pavan., A novel fault diagnosis technique for photovoltaic systems based on artificial neural networks, Renew. Energy, 90, 11(2016).

12. M. Dhimish, V. Holmes, B. Mehrdadi, M. Dales, Comparing Mamdani Sugeno fuzzy logic and RBF ANN network for PV fault detection, Renew. Energy, 10 (066), 2017.

13. S. Das, A. Hazra, M. Basu., Metaheuristic optimization based fault diagnosis strategy for solar photovoltaic systems under non-uniform irradiance, Renew. Energy, 118, 15(2017). 